\title{
GRAN MINERÍA Y LOCALIDADES AGRÍCOLAS EN EL NORTE DE CHILE: COMPARACIÓN EXPLORATORIA DE TRES CASOS ${ }^{1}$
}

\author{
LARGE MINING AND AGRICULTURAL LOCALITIES IN \\ NORTHERN CHILE: EXPLORATORY COMPARISON OF THREE CASES
}

\author{
Matías Calderón ${ }^{1}$, Catalina Benavides ${ }^{1}$, Javier Carmona ${ }^{1,2}$, Damián Gálvez ${ }^{1,3}$, Natalia Malebrán ${ }^{1}$, \\ Manuela Rodríguez ${ }^{1}$, Denise Sinclaire ${ }^{1}$ y José Urzúa ${ }^{1}$
}

\begin{abstract}
Presentamos los resultados de un estudio exploratorio y cualitativo acerca de las transformaciones agrarias y los conflictos hídricos que han emergido en las últimas tres décadas entre localidades históricamente agrícolas y grandes empresas mineras en el norte de Chile. Investigamos en tres casos de estudio: Quillagua (comuna María Elena, Región de Antofagasta), Peine (comuna San Pedro de Atacama, Región de Antofagasta) y Los Loros (comuna Tierra Amarilla, Región de Atacama). A partir del discurso de los entrevistados, efectuamos una reconstrucción histórica de los cambios centrándonos en tres dimensiones interrelacionadas que permiten abordar el problema: características de las actividades agropecuarias, presencia y vínculos con la minería, y situación de los recursos hídricos.
\end{abstract}

Palabras claves: gran minería, localidades agrícolas, conflictos hídricos, norte de Chile.

We present the results of an exploratory and qualitative research about on the agrarian transformations and the water conflicts that emerged the last three decades between localities historically agrarian and large mining companies in northern Chile. This research consists of three case studies: Quillagua (Municipality of María Elena, Antofagasta Region), Peine (Municipality of San Pedro de Atacama, Antofagasta Region) and Los Loros (Municipality of Tierra Amarilla, Atacama Region). Based on the interviewees's discourse, we elaborate a historical reconstruction of the changes, focussing on three interrelated dimensions that tackle the problem: characteristics of agricultural activities, presence and ties to mining, and the situation of the hydric resources.

Key words: Large mining, agricultural localities, hydric conflicts, northern Chile.

El neoliberalismo ${ }^{2}$, impulsado desde mediados de la década de 1970 en Chile y durante la de 1980 en el resto de América Latina, ha implicado la intensificación de las exportaciones de recursos naturales por parte de la región (Comisión Económica para América Latina y el Caribe [CEPAL] 2012), proceso manifestado en Chile en el aumento de actividades frutícolas, silvícolas, acuícolas y mineras. Esta última, principal exportación del país desde el siglo XIX, experimentó entre 1990 y 2010 un crecimiento inédito basado en capitales nacionales y extranjeros (Cantallopts et al. 2007; Guajardo 2007).

La minería utiliza en su proceso productivo volúmenes importantes de agua, con lo cual, su incremento ha implicado dinámicas de conflicto entre grandes empresas y actores locales por su control, uso, almacenamiento y contaminación. Disputas por el agua son observables en Chile y otros países de América Latina, donde la mayoría de los actores locales corresponden (o correspondieron) a comunidades campesinas (agricultura familiar), algunas de estas reivindican con mayor o menor fuerza una identidad étnica (Alimonda 2011; Bebbington et al. 2007; Castro 1997; Díez 2007; Fernández y Salinas 2012; Gundermann 2013; Instituto Nacional de Derechos Humanos [INDH] 2012; Larraín y Poo 2010; Machado 2010; Molina 2013; Yáñez y Molina 2008). En Chile la mayoría de las faenas de la megaminería se llevan a cabo en el norte del país, área donde residen comunidades ${ }^{3}$ aymaras,

1 Grupo de Investigación en Ciencias Sociales y Economía, Universidad Academia de Humanismo Cristiano, Condell 506, Santiago, Chile.mcalderonseguel@gmail.com; catabenavides.a@gmail.com; nataliamalebran@gmail.com; mrodricareaga@gmail.com; sindenise@gmail.com; josemiguelurzua@gmail.com

2 Fundación Desierto de Atacama, Santa Victoria 45, Santiago, Chile. javier.carmona.y@ gmail.com

3 International Institute for Philosophy and Social Studies, Berlín, Alemania. damiangalvezgonzalez@gmail.com

Recibido: enero 2015. Aceptado: octubre 2015.

http://dx.doi.org/10.4067/S0717-73562016005000001. Publicado en línea 2-febrero-2016. 
atacameñas, collas, diaguitas y quechuas, como también población sin adscripción indígena.

Las contradicciones insoslayables entre la explotación intensiva de recursos naturales a gran escala y el resguardo de ecosistemas que permitan la reproducción de la vida en condiciones óptimas, configuran diversas interrogantes de máxima importancia, por ejemplo, por las transformaciones de los grupos humanos que han habitado históricamente estos espacios en sus distintos ámbitos: modos de subsistencia; arreglos sociales sobre gestión y uso del agua (y otros recursos naturales); patrones de organización sociopolítica; acciones de adecuación o resistencia; y por las diversas formas en que estos procesos se significan. En este estudio nos preguntamos en concreto, ¿cuáles han sido los cambios experimentados en los sistemas productivos?, ¿cómo se han relacionado las localidades con las empresas? $\mathrm{y}$ ¿de qué modo ha variado la disponibilidad de agua y las formas de entender y gestionar el recurso?

Con este artículo pretendemos aportar mayores antecedentes, desde lo local, como una manifestación de lo general (Comas d' Argermir 1998; Trinchero et al. 2007; Wolf 2000), al necesario debate que debe hacerse acerca del modelo económico, fundamentalmente extractivista, que ha seguido Chile y la mayoría de los países de América Latina.

\section{Metodología}

La recopilación de los discursos fue mediante entrevistas semiestructuradas guiadas a partir de los ejes temáticos del proyecto (actividades agropecuarias, relación con grandes mineras y situación de los recursos hídricos), las que fueron aplicadas a informantes claves de cada localidad, procediendo por el principio de saturación de la información. Para abordar la situación actual lo anterior se complementó con observación participante y no participante.

El análisis sistematizó la información a través de las categorías ya mencionadas, para luego efectuar una reconstrucción de la historia oral de cada localidad (complementada con fuentes secundarias), desde años previos al neoliberalismo hasta el momento del trabajo de campo (año 2013).

\section{Los Casos}

Son tres localidades rurales del norte del país, cercanas a yacimientos mineros importantes, donde su población ha subsistido históricamente a partir de la actividad agropecuaria. Se ubican en tres cuencas nortinas que se pueden visualizar en la Figura 1; Quillagua, en el sector medio-inferior del río Loa (comuna María Elena); Peine, en la cuenca del salar de Atacama (comuna San Pedro de Atacama), y Los Loros, en el río Copiapó (comuna Tierra Amarilla). Las dos primeras se sitúan en la Región de Antofagasta (norte árido) y la tercera en la Región de Atacama (norte semiárido).

Son territorios con histórica presencia indígena, reconocida formalmente por el Estado con la constitución legal de las siguientes comunidades jurídicas: Comunidad Indígena Aymara de Quillagua (2003), Comunidad Indígena Atacameña de Peine (1995), mientras que en los Loros se han conformado tres: Comunidad Indígena Pacha Churicai (2001), otra conformada por personas de Los Loros y lugares aledaños -Comunidad indígena Colla Wayra Manta Tujsi (2001)-,y la Comunidad Indígena Colla Tata Inti, Pueblo Los Loros (s/i) ${ }^{4}$. Más allá de las organizaciones legales, importa precisar que -al menos al momento del trabajo de campo- la adscripción étnica variaba en los distintos casos, mientras en Quillagua y los Loros existe población que no se autopercibe como indígena, en Peine prácticamente la totalidad de sus habitantes se identifica como atacameño, formando parte de la comunidad jurídica.

\section{Marco Legal}

En Chile la legalidad neoliberal referente a los temas tratados se ha expresado en el Estatuto de Inversión Extranjera de 1974, el Código de Aguas (CA) de 1981, la Nueva Ley de Concesiones Mineras de 1982 y el Nuevo Código de Minería de 1983. Las normativas vinculadas a la minería, junto con el alza internacional de los precios del cobre, le han otorgado un estímulo sin precedentes, expresado en la abertura de nuevos yacimientos y en el aumento de la producción de los ya existentes. Esto ha conllevado diversos problemas medioambientales, donde los relativos al agua cumplen un papel central (Folchi 2003; Guajardo 2007).

Además, el CA de 1981 ha generado la privatización, desregulación y mercantilización del agua, generando usos indiscriminados, escasez y especulación (Bauer 2002; Castro 1997; Castro y Quiroz 2011; Gentes 2004; Larraín y Poo 2010). Un reciente informe del Ministerio de 


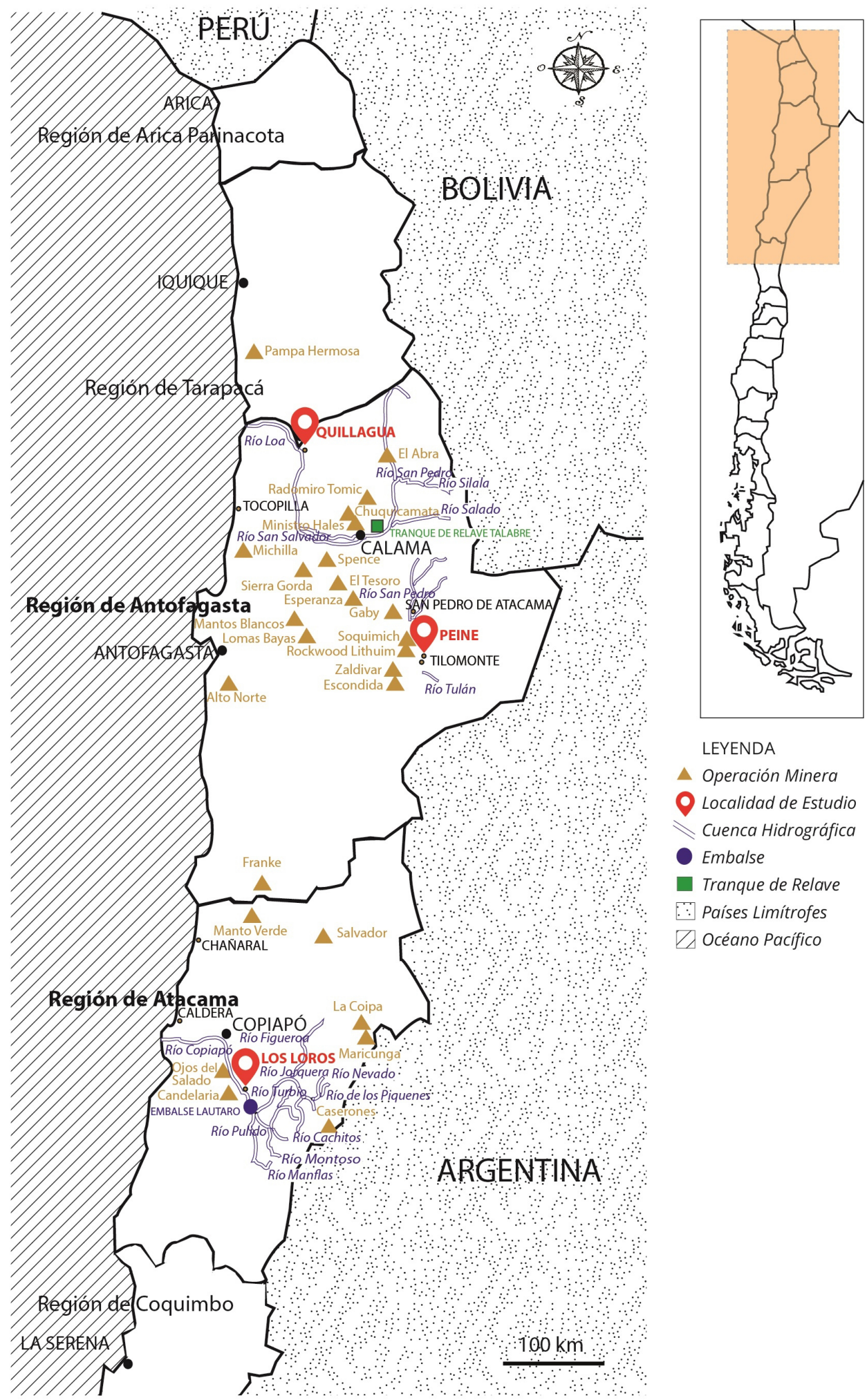

Figura 1. Mapa de localización de casos de estudio y aspectos relevantes (elaborado por Natalia Malebrán con apoyo de Paz Rebolledo). Map of location of case studies and relevant aspects (prepared by Natalia Malebrán with the help of Paz Rebolledo). 
Obras Públicas (MOP) (2013) sincera que la mayoría de las principales cuencas del país (con actividad minera y otras actividades primarias) se encuentran sobreexplotadas o con los derechos de aprovechamiento $^{5}$ sobreotorgados.

\section{Antes del Neoliberalismo}

Quillagua $^{6}$ presentó desde inicios del siglo XX hasta la década de 1970 su "edad de oro agrícola" basada en la producción de maíz y alfalfa orientada al mercado nortino macrorregional. Paralelamente, su población extrajo y pescó camarones y pejerreyes del río Loa, especies destinadas al autoconsumo e intercambio. El comienzo de la centuria coincide con el fortalecimiento de la articulación mercantil con las salitreras de la región, las que cumplieron un rol central en la consolidación de la agricultura comercial. La alfalfa era comprada por arrieros procedentes del noroeste argentino que viajaban hacia las oficinas salitreras, mientras que el maíz era vendido en mercados formales e informales de la pampa (Odone 1995).

La inserción de Quillagua en circuitos dinámicos de acumulación capitalista, junto con el arribo de foráneos en busca de trabajo y mejores oportunidades de vida, impulsó un acceso desigual a la tierra entre algunos habitantes de la localidad, lo que promovió vínculos salariales entre ellos, como también, venta de fuerza de trabajo en fincas forrajeras controladas por capitales extranjeros residentes en el valle.

Las memorias sobre la "edad de oro agrícola" hablan de disponibilidad de agua en abundancia. Esta se administraba colectivamente bajo mecanismos consuetudinarios, en específico, por medio de la existencia de un "juez de agua" decretado por los lugareños, quien debía velar por el cumplimiento del orden, respeto y equidad del riego, aspectos definidos en función de la propiedad (hectáreas controladas) y necesidad de las familias (cultivos). El recurso hídrico se distribuía a partir de dos canales antiguos que permitían la irrigación mediante riego por tendido. En este período los canales eran eje de la práctica comunitaria económico-festiva de la "limpia", la cual-como se conoce- cumple un rol relevante no solo por implicar el mantenimiento necesario de la infraestructura productiva, sino que en la vida social en general de los pueblos andinos, ya que fortalece los vínculos comunitarios y con las divinidades ${ }^{7}$.
Por su parte, durante el siglo XX la agricultura en Peine ${ }^{8}$ estaba orientada a la producción de maíz y alfalfa, y en menor medida a olivos y hortalizas, junto a ganadería caprina, ovina, pastoreo de camélidos y caza de chinchilla. La fracción mayoritaria de esta producción estuvo orientada al autoconsumo, a excepción de la caza de chinchilla, cuyas pieles eran intercambiadas dentro y fuera de la región, generando un ingreso monetario a partir de la producción local (Benedetti, 2003). Los vínculos con los mercados en la misma localidad eran muy menores respecto de los que presentaban los habitantes de Quillagua, dominando -por lo tanto-relaciones de producción de tipo doméstico. Quienes deseaban aumentar su ingreso monetario emigraban para asalariarse en extracción de sal en Argentina, en la construcción del ferrocarril Salta-Antofagasta (Huaytiquina) y en la minería en Chuquicamata (Núñez 2000).

En la década de 1960 se recuerda un aumento de la minería en torno al Salar de Atacama y consecuentemente una mayor demanda de trabajadores. Esto acrecentó las posibilidades de obtener un ingreso salarial cerca del poblado y muchos hombres jóvenes postergaron el trabajo agrícola para incorporarse al nuevo empleo. Esto redujo la fuerza de trabajo agropecuaria afectando parte de su capacidad productiva. Lo anterior fue el punto de partida de un proceso que se ampliará desde 1980, experimentado en general en el área atacameña (Gundermann 2013).

Las fuentes de abastecimiento de agua han sido históricamente dos vertientes (Wilte, cercana a Peine y Tulán, próxima al espacio de cultivos de Tilomonte). Se percibe un pasado que sin ser de abundancia tampoco es de escasez, sin embargo, las aguas de estas vertientes son salobres y con alto boro, con lo cual, presentan problemas para el consumo humano, existiendo recuerdos de períodos donde la adquirían a camiones aljibe de la minera Sociedad Chilena del Litio (SCL) (hoy Rockwood Litio Limitada), que compraba agua a Toconao y la vendía a Peine, estableciéndose de esta forma ciertos vínculos de dependencia. La provisión de agua fue solucionada en 1997 cuando la comunidad logra erigir con apoyo de Rockwood Litio Limitada, luego de diversos esfuerzos, un sistema de abastecimiento desde la cercana laguna Miscanti.

En tiempos preneoliberales y actuales, el uso del agua ha estado gestionado por el Consejo de Agricultores (propietarios de tierras) quienes 
supervisan su uso mediante la designación de un "celador de riego" que vela por una distribución adecuada según extensión predial y tipo de cultivo. $\mathrm{El}$ recurso es almacenado en tranques (Pailabote, San Francisco y Tranque Chico) y distribuida por una red de canales de tiempos inmemoriales. El Consejo es la institución que se encarga hasta hoy de la "limpia de canales", una de las más relevantes expresiones de la ritualidad agrícola en la localidad.

Durante gran parte del siglo XX en Los Loros ${ }^{9}$ se dedicaron a la chacarería para autoconsumo (melones, sandías, granadas, tunas, tomates y cebollas), al cultivo de cítricos orientados a mercados regionales (mandarinas y naranjas) y a la ganadería caprina para autoconsumo. Eran pequeños y medianos productores con importante presencia de relaciones de trabajo doméstico. Solo en la cosecha existían vínculos asalariados entre los que poseían mayor tierra y los que controlaban menos.

Estos tiempos se recuerdan como de mayor solvencia económica en comparación a los actuales, las naranjas tenían fama regional, siendo un componente de identidad local. Los informantes resaltan que algunos agricultores contrataban personal para trabajar en sus parcelas como un indicador de esa mayor capacidad productiva. En este sentido, la llegada del ferrocarril en 1945 da cuenta del alto flujo de mercancías agrícolas y pirquineras en la zona (Griem 2003).

Hasta la década de 1980 los habitantes de Los Loros no tenían problemas para acceder a las aguas del río Copiapó, principal fuente de riego. Son tiempos percibidos como abundantes, destacándose sus usos recreacionales en la ribera del río. Las aguas de riego provenían del embalse Lautaro (Sandoval 2003), la irrigación era efectuada mediante un sistema de canales donde la distribución recaía en un "juez de aguas" que lo hacía según necesidad de los agricultores en función de las hectáreas controladas. En este caso, no hay menciones a la limpia de canales como una instancia festiva-ritual específica. Más allá de este dato, al igual que en Quillagua y Peine, la forma de organización del riego y los criterios involucrados permiten inferir una concepción del agua como bien comunitario a disposición de todos los que lo necesitaran. Finalmente, es importante destacar que no existen referencias a la pequeña minería del río Copiapó como un elemento que presionaba al recurso hídrico.

\section{Transformaciones Neoliberales}

Quillagua, luego de su vigoroso pasado, es hoy la localidad que presenta el estado más crítico de las tres en lo que respecta a la calidad y disponibilidad de agua. Exhibe una fuerte crisis agropecuaria junto con un consecuente despoblamiento, derivado de acontecimientos ligados al impacto de la gran minería en el territorio. La agricultura está al borde de su desaparición y la disponibilidad de aguas de regadío es prácticamente nula (Bustos, 2001), aspectos que evidentemente dificultan y reducen la práctica agraria-ritual de la limpia de canales. Los cultivos de orientación mercantil junto con la extracción y pesca de especies del Loa ya no existen, solo se practica una agricultura residual, abastecedora del forraje del reducido ganado local.

Desde mediados de la década de 1970 hasta inicios del 2000 hubo una serie de episodios de intervención y contaminación del río Loa, los cuales son imputados como causantes de la merma hídrica. Un evento relevado por los entrevistados es la construcción del embalse Conchi (1975), cuyas aguas serían almacenadas para las actividades agropecuarias de la zona, pero según la percepción local han sido derivadas hacia la gran minería. También se evoca la anterior captación de Lequena (1972) para consumo urbano y la aducción de Quinchamale (1985) como intervenciones que fueron reduciendo progresivamente la disponibilidad hídrica. En las últimas décadas se enuncian dos episodios de contaminación, acontecidos en 1997 y 2000. A nivel local estos se interpretan como el "golpe de gracia" a la agricultura.

Vigente el CA de 1981 se denuncia que durante la regularización de las aguas la mayoría de los habitantes -desconocedores en ese entonces de la nueva normativa- fueron engañados por agentes del Estado, quedando con escasos derechos. Por ejemplo, fueron atemorizados con futuros "pagos" por el uso de agua, desvalorizándose el número de litros usados según hectáreas. También, al haber disponibilidad de agua en ese tiempo, la urgencia de la inscripción de derechos no era vista como imprescindible por los agricultores. En definitiva, a diferencia de parte importante del siglo XIX y $\mathrm{XX}$, donde actividades mineras propulsaron la articulación de Quillagua con mercados de la región, hoy estas son concebidas como una "maldición", causa de la crisis agraria y demográfica. 
Luego de los episodios de contaminación de 1997 y 2000, muchos de los lugareños fueron instigados a vender sus derechos de aprovechamiento a la gran minería, en particular a la empresa Sociedad Química y Minera de Chile (SQM). Esto provocó conflictos internos entre quienes deseaban conservar sus derechos y los que daban todo por perdido. Los primeros aún perciben que lo ocurrido constituye una "traición" a la tradición agrícola, mientras que los segundos aluden que ellos simplemente vendieron "papeles secos".

Es en este contexto que en 2003 -como parte de un proceso mayor de emergencia de la identidad aymara en Chile desde mediados de la década de 1990 (Gundermann et al. 2013) - es fundada por algunos residentes la Comunidad Indígena Aymara de Quillagua, cuya razón de ser y posición inicial fue restituir a la localidad los derechos de agua traspasados a la industria minera y formalizar la inscripción de un amplio territorio bajo fundamento de preexistencia y ocupación ancestral (McPhee 2010).

Un nuevo relacionamiento entre la comunidad y la gran minería se genera el 2008 a partir de la intención de SQM de desarrollar el proyecto de extracción de yodo y nitrato Pampa Hermosa en el Salar de Llamara, cuya propiedad es reivindicada por la Comunidad Indígena (Barros 2010). Luego de un enmarañado proceso de negociación y debates internos entre la comunidad y la empresa, esta última ofreció financiar un plan de desarrollo local, en curso pero por ahora sin resultados visibles. Las valoraciones negativas hacia los efectos de la gran minería en la localidad, sin embargo, parecieran ser matizados fruto de las expectativas respecto del referido plan.

En Peine las prácticas agropecuarias aún están difundidas al interior de la localidad, pero complementan a las actividades asalariadas; parte de la población en edad laboral ha relegado las actividades agropecuarias por la creciente demanda minera desde 1960 en adelante (empleo directo o proporcionando servicios). La agricultura solo se practica para autoconsumo, cosechando principalmente maíz, hortalizas, alfalfa y olivos. La ganadería, antes de ovejas, cabras y pastoreo de camélidos, se limita en la actualidad a la crianza caprina en corrales. Si bien existieron instancias de emigración laboral en el pasado, se recuerda a la agricultura y ganadería como actividades que tenían la capacidad de proporcionar bienestar por sí mismas.
Con todo, la disminución agropecuaria no ha afectado su rol simbólico como articulador colectivo mediante la limpia de canales, instancia donde el "pago o convido" a los cerros y la ceremonia del "Talatur" (se canta, baila y pide por un provechoso ciclo agrícola), constituyen un importante acontecimiento que no solo refiere a la eficiencia productiva, sino también a prácticas que conllevan cohesión y reafirmación comunitaria.

A pesar de que desde 1980 han aumentado las operaciones mineras en las inmediaciones del salar de Atacama-orientadas a la extracción de litio por parte de Rockwood Litio Limitada y SQM, y cobre por Minera Escondida ${ }^{10}$, los informantes de esta localidad no experimentan, ni perciben, una situación crítica del agua en su poblado. Los discursos indican que no existe disminución ni contaminación de las fuentes hídricas, ya que los recursos utilizados por las empresas se encuentran "bajo" el salar de Atacama, mientras que los de Peine "sobre" este. Sin embargo, saben de los efectos de las grandes mineras en otras áreas, expresando preocupación y alerta ante el riesgo constante. La inexistencia de interés minero explícito hasta mediados de la década del 2000 por las aguas que son de la comunidad, hace que el CA de 1981 no haya significado un episodio catastrófico como lo fue para Quillagua.

El agua de consumo doméstico es de libre acceso para todos los habitantes de la localidad quienes solo deben poseer el derecho inicial para cada hogar. Derecho que en los primeros años de la habilitación del sistema dependía del trabajo realizado durante las faenas de canalización, actualmente la entrega de nuevos derechos requiere de un pago monetario único. La gestión del sistema de agua dulce está a cargo del Comité de Agua Potable de Peine. Si bien la canalización de agua significó su disponibilidad, presenta deficiencias en su acceso y distribución. Ejemplo de lo anterior son las tensiones por la proliferación local de servicios de hospedaje y alimentación incentivados por la minería, que presionan al recurso en pos de un beneficio particular, perjudicando en ocasiones al resto de los habitantes.

Durante 2006 y 2007 se presentó un conflicto hídrico abierto con la industria cuprífera que involucró a Peine y otras localidades atacameñas. Minera Escondida pretendía la realización de un gran proyecto de extracción hídrica en la zona de Pampa Colorada (emplazada al sureste de Peine en el altiplano, cercana también 
a Socaire, Camar, Talabre y Toconao). En oposición a ello las comunidades indígenas se coordinaron e impulsaron asociatividad y pujaron con movilización social y por la vía legal por el rechazo del proyecto; lo que finalmente se logra (Azócar 2015; Bolados 2014).

Lo anterior es destacado por los informantes como un gran logro atacameño de organización y movilización que debe ser replicado. A partir de ello se formalizan vínculos entre Peine y algunas de las más importantes empresas mineras de la zona, estableciéndose así una relación donde la comunidad ha expresado su capacidad de negociación y exigencias, destacando el cumplimiento de compensaciones, regulación de externalidades negativas y participación de las empresas en diferentes proyectos. Este vínculo se ha materializado en un convenio entre la comunidad indígena y las grandes empresas con alcances sin precedentes en Chile de acuerdo con sus exigencias de cumplimiento de los principales instrumentos normativos nacionales e internacionales en materia indígena.

A diferencia de Quillagua y Peine, la gran minería en las cercanías de Los Loros surge en el relato de los sujetos solo para las décadas recientes. Son dos las empresas que fueron señaladas por los informantes como influyentes en su territorio: Candelaria y Caserones. La primera opera desde inicios de la década de 1990, la segunda está aprobada desde 2008 y comenzaría a operar el 2014, siendo un proyecto que durante su instalación ha generado resistencia por parte de la población.

Las transformaciones de las actividades agropecuarias de Los Loros ocurren por procesos del propio agro, articulándose con la minería en la década de 1990. La vigencia del CA de 1981 se presenta en paralelo a un proceso de reducción de la agricultura familiar, quienes por necesidades económicas o seducidos por la posibilidad de obtener una suma considerable de dinero comienzan a vender sus tierras a grandes empresarios agrícolas para el cultivo de vid de exportación, actualmente la pequeña agricultura es casi inexistente en la localidad.

La desaparición de la agricultura familiar estuvo acompañada de una creciente proletarización de la población. Esto quiere decir que los habitantes de Los Loros venden su fuerza de trabajo de modo estacional a las empresas exportadoras de uva de mesa de la región. Mantienen la posibilidad de obtener un ingreso monetario en la zona, pero ahora no por medio de la introducción de sus propios productos en el mercado.

La alta demanda de mano de obra implica importantes movimientos de trabajadores y trabajadoras que llegan y se van según el ciclo agrario en todo el valle de Copiapó (Valdés 2012). En Los Loros esto ha generado que muchos de ellos en vez de retornar a sus lugares de origen hayan optado por quedarse en la localidad levantando viviendas informales en la parte alta del pueblo. Esto no solo ha configurado un problema social a partir de la existencia de sectores de la población en precarias condiciones, sino que también conflictos internos entre los habitantes históricos e inmigrantes temporeros por recibir beneficios sociales del municipio y mineras.

La pérdida de la tierra y su consecuente desvinculación con el agua para fines productivos hizo que en Los Loros no hayan experimentado conscientemente la implementación del CA de 1981. En paralelo a la privación de la propiedad de la tierra, ocurre de modo oculto a la percepción de los habitantes la privatización del agua. Simultáneamente la agricultura empresarial se expande a los cerros y se posiciona en espacios circundantes al río que anteriormente eran de libre acceso, hoy privados y de ingreso restringido, que se ocupaban para actividades de esparcimiento.

Con el comienzo de las grandes operaciones mineras en la zona se inicia un traspaso de derechos de aprovechamiento desde la agricultura capitalista a la gran minería. Parte de los exportadores agrarios optan por vender sus derechos y se trasladan a otras cuencas; esto reduce la producción agrícola y la demanda de trabajadores. La disminución del empleo agrícola impacta directamente en el ingreso local, tanto en los históricos habitantes que vendieron sus tierras como en los inmigrantes que llegaron en el ir y venir de temporeros. Es recién con esto que se evidencia para la población la lógica mercantil y privatizadora del agua. Los informantes reflexionan respecto del descenso de la agricultura y expresan una mezcla de incertidumbre, pesimismo y resignación. En esta localidad, la minería, al menos por el momento, no ha abierto nuevas fuentes de empleo.

Los vínculos de la población con la gran minería tienen un carácter dual. Se ha señalado que personas de la capital comunal Tierra Amarilla tienen una relativa percepción positiva de la mina Candelaria, ya que ha generado empleo, capacitaciones y beneficios. Pero en Los Loros no han sido mayormente 
destinatarios de ellos, se han creado ilusiones pero que en la práctica no se concretan y que por ello, a fin de cuentas, genera impactos negativos. Ante los problemas de disponibilidad de agua, la empresa ha fomentado la instalación de pozos para los pequeños agricultores que aún subsisten; con ello aseguran un vínculo de dependencia, y, además, crean un inhibidor de acciones públicas de descontento.

Las valoraciones sobre Caserones son abiertamente contrarias. En un primer momento existió la esperanza de que se abrirían nuevos puestos de trabajo, algo que ocurrió en faenas de construcción cuando se erigieron los campamentos, pero luego los vínculos laborales se detuvieron. En su reemplazo han existido vínculos a través de fondos concursables y algunos aportes a la infraestructura local. A pesar de este tipo de relaciones, no hay conformidad con la presencia de la mina considerando el impacto en la reducción del empleo agrícola. Sin tener una alternativa laboral, el efecto de los proyectos sociales se minimiza.

Hasta el momento del estudio de campo, la dimensión indígena había jugado un rol menor en los conflictos. Informantes entrevistados se posicionaban desde su identidad colla para erigir un discurso que reivindicaba la recuperación del agua, pero aún no se había materializado en organización y acciones contestatarias. De lo anterior es importante considerar que desde la década de 1990 en Los Loros se produce un proceso de identificación étnica bastante acelerado y complejo, como en toda la población colla (Molina 2013; Quiroz y Jeria 2010). Aunque no todos los habitantes de la localidad se identifican como indígenas y este componente aún no está en el centro de las prácticas y visiones críticas, los vínculos existentes entre mineras y otras comunidades colla de la zona (Molina 2013) posibilitan su fortalecimiento.

\section{Conclusiones}

Los datos expuestos constatan los contradictorios procesos de cambio social forzado que experimentan las poblaciones de los territorios donde el capitalismo neoliberal penetra, profundizando las dinámicas orientadas a la acumulación bajo un esquema extractivista dominado por grandes corporaciones que operan con un marco legal favorable.

La situación hídrica en cualquier territorio de Chile, incluyendo estos tres casos, está relacionada con la privatización del agua. La "mercantilización de todas las cosas" (Wallerstein, 2003), tendencia capitalista radicalizada con el agua, va en directa contradicción con la subsistencia de mediano y largo plazo de los grupos humanos que habitan los territorios donde operan las grandes industrias extractivas.

Sin embargo, la trayectoria, el entorno y las características de las poblaciones afectadas toman caminos divergentes. Los factores específicos promueven impactos y respuestas diferentes a la presencia de las grandes mineras. En este sentido, la dimensión étnica en un contexto de identidades emergentes y creciente respaldo institucional (Ley 19.253, Convenio 169 de la OIT y Declaración de la ONU sobre derechos de los pueblos indígenas) sugiere presentar algunas potencialidades para que los actores locales puedan fortalecer su control en el territorio y sus recursos, rechazando o regulando el extractivismo, como también disputando parte de los beneficios de su presencia.

La concepción del agua como recurso transable fue una imposición estructural de la dictadura cívicomilitar (1973-90), lo que implicó progresivamente un reajuste conflictivo en los sistemas de significados que los propios actores tenían respecto de sus dinámicas y vínculos con el medioambiente. Acontece un diálogo asimétrico por el agua, acervo de una variedad amplia de matices y configuraciones complejas e incluso contradictorias que pueden transitar y conjugarse desde una concepción mercantil orientada a la rentabilidad, hasta una visión sagrada, integral y conducente a reproducir el ciclo de la vida (Vargas 2006).

En los casos de estudio, antes del neoliberalismo, y más allá de la presencia étnica, el agua era pensada y utilizada desde códigos no mercantiles, era entendida como un bien comunitario. El agua como mercancía es en un primer momento un lenguaje y condición inimaginable, casi impracticable de un recurso que históricamente había estado a libre disposición. En este marco, los efectos de la privatización hídrica son disímiles, en Quillagua fueron engañados y despojados; en Peine, debido a su organización, pudieron llevar a cabo un convenio; y en los Loros aconteció una venta prematura y podría vislumbrarse un incipiente proceso de organización.

A la par que se intensifica la idea mercantil del agua en los territorios y se da una progresiva reconfiguración de prácticas y concepciones a este esquema, se producen dinámicas de desmercantilización de algunos ámbitos, como 
intensificación en la mercantilización de otros. Por ejemplo, en Quillagua los productos agrícolas dejan de concebirse y tratarse como intercambiables. En Peine, mientras las actividades agropecuarias pierden importancia, se experimenta una creciente proletarización vinculada a la minería y actividades anexas. Por su parte, en Los Loros se consolida completamente la noción del trabajo humano como mercancía mientras se devela la lógica mercantil del agua, que en un primer momento quedó oculta.

En el ámbito hídrico-ritual es posible sostener que están íntimamente ligados a los procesos agrícolas orientados a la producción del mundo material y del universo simbólico en los cuales se circunscriben. En el caso de Quillagua, el despojo del agua ha disminuido la actividad agrícola y así los lazos sociorreligiosos emanados de la limpia de canales. En Peine, debido a la manera en la que pudieron defender sus intereses y las actividades relacionadas con el cuidado de la infraestructura hídrica, se ha fortalecido el respeto por los vínculos sociales y el culto a las deidades. En Los Loros, a pesar de los altos grados de proletarización, ciertos sectores de la población colla construyen discursos relativos al agua que apuntan a sus dimensiones supraterrenales. Otro sector, de tradición cristiana no indígena, estima que el origen del recurso es divino, por lo cual es necesaria su preservación.

Finalmente, los tres casos muestran las múltiples relaciones (y direcciones) entre historia, medio ambiente, sistemas productivos, clase social, política e identidad. Por lo tanto, no existe un procedimiento inequívoco que permita deducir sin investigación cuál de los factores mencionados será el preponderante frente a un conflicto, o cómo se conjugarán en la práctica. La única certeza, por tanto, es una antropología que imbrique indisolublemente estos elementos en contextos históricos, sociales y territoriales dinámicos que, no puede olvidarse ni omitirse, se desenvuelven como expresiones concretas del capitalismo global.

Agradecimientos: A todas las personas de Quillagua, Peine y Los Loros que colaboraron con nosotros. De igual modo, a los evaluadores anónimos por sus valiosas sugerencias.

\section{Referencias Citadas}

Alimonda, H. (coord.) 2011. La Naturaleza Colonizada. Ecología Política y Minería en América Latina. CLACSO/ CICCUS, Buenos Aires.

Azócar, R. 2015. Pampa Colorada. Conflicto Etno-ambiental y Movimiento Indígena Atacameño. Memoria para optar al título de Antropólogo Social, Departamento de Antropología, Universidad de Chile, Santiago.

Barros, A. 2010. Genocidio en Pampa Hermosa: el gobierno contra la comunidad aymara de Quillagua (22 septiembre). http://www. elquintopodercl/medio-ambiente/genocidio-en-pampa-hermosa-elgobierno-contra-la-comunidad-aymara-de-quillagua (4 junio 2015).

Bauer, C. 2002. Contra la Corriente. Privatización, Mercados de Agua y el Estado en Chile. Lom, Santiago.

Bebbington, A., D. Humphreys, J. Bury, J. Lingan, J. Muñoz y M. Scurrah 2007. Los movimientos sociales frente a la minería: disputando el desarrollo territorial andino. En Territorios Rurales. Movimientos Sociales y Desarrollo Rural en América Latina, editado por J. Bengoa, pp. 283-315. Catalonia/RIMISP, Santiago.

Benavides, C. y D. Sinclaire 2014a. Inserción Capitalista en un Oasis Atacameño. Peine Tradición Minera y Gran Minería en la Cuenca del Salar de Atacama. Tesis para optar al grado de Licenciado en Antropología y título de Antropólogo, Escuela de Antropología, Universidad Academia de Humanismo Cristiano, Santiago.

Benavides, C. y D. Sinclaire 2014b. El convenio minero en tierras indias. El Oasis de Peine y la gran minería en la cuenca del Salar de Atacama. Revista Rufián 19:31-39.
Benedetti, A (compil.) 2003. Puna de Atacama. Sociedad, Economía y Frontera. Alción, Córdoba.

Bolados, P. 2014. Los conflictos etnoambientales de Pampa Colorada y El Tatio en el Salar de Atacama, Norte de Chile. Procesos étnicos en un contexto minero y turístico transnacional. Estudios Atacameños 48:229-248.

Bustos, A. 2001. Impacto socioeconómico del deterioro agrícola en Quillagua (II Región, Chile). Actas IV Congreso Chileno de Antropología Tomo II, pp. 733-743. Universidad de Chile, Santiago.

Calderón, M., R. Díaz, C. Morales, A. Mühle, M. Rodríguez, R. Rojas, V. Torres y J. Villaseca 2013. Territorios rurales y neoliberalismo en Chile. Conflictos económicos y sus expresiones políticas en zonas de vitivinícolas, forestales e industrias salmoneras. Cuadernos de Antropología Social 38:153-176.

Cantallopts, J., P. Pérez y R. Molina 2007. Análisis histórico y estimaciones futuras del aporte de la minería al desarrollo de la economía chilena. En Bonanza Minera: Oportunidades y Riesgos, recopilación de la Comisión Chilena del Cobre (COCHILCO), pp. 21-61. COCHILCO, Edición Digital. http://www.cochilco. cl/descargas/estadisticas/recopilacion/2007.pdf (6 agosto 2014).

Carmona, J. 2013. Genealogía de un Ocaso Agrícola. Estructura Agraria y Reetnificación en el Valle de Quillagua. Desierto de Atacama, II Región de Antofagasta, Chile. Tesis para optar al grado de Licenciado en Antropología y título de Antropólogo, Escuela de Antropología, Universidad Academia de Humanismo Cristiano, Santiago. 
Carmona, J. 2014. La larga duración del capital en el Desierto de Atacama y el advenimiento de la sequía del río Loa: un repaso desde el valle de Quillagua. Revista Rufián 19:19-29.

Castro, M., M. Bahamondes, M. Goio y C. Meneses 1992. Cultura Hídrica: un Caso en Chile. UNESCO-ORCAL, La Habana.

Castro, M. 1997. Agua, derechos y cultura en los Andes del norte de Chile. Un enfoque desde la antropología jurídica. Chungara 29:63-80.

Castro, V. y J.L. Martínez 1996. Poblaciones indígenas de Atacama. En Culturas de Chile. Etnografía. Sociedades Indígenas Contemporáneas y su Ideología, editado por J. Hidalgo, V. Schiappacasse, H. Niemeyer, C. Aldunate y P. Mege, pp. 69-109. Editorial Andrés Bello, Santiago.

Castro, M. y L. Quiroz 2011. La crisis del mercado de agua en Chile: el futuro de Chile requiere de una nueva política de agua. En Justicia Hídrica. Acumulación, Conflicto y Acción Social, editado por R. Boelens, L. Cremers y M. Zwarteveen, pp. 225-241. Fondo Editorial, Lima.

Comas d' Argemir, D. 1998. Antropología Económica. Ariel, Barcelona.

Comisión Económica para América Latina y el Caribe (CEPAL). 2012. Cambio Estructural Para la Igualdad. Una Visión Integrada del Desarrollo. CEPAL, Santiago.

Díez, A. 2007. Ronderos y alcaldes en el conflicto minero de Río Blanco en Piura, Perú. En Territorios Rurales. Movimientos Sociales y Desarrollo Rural en América Latina, editado por J. Bengoa, pp. 432-443. Catalonia/RIMISP, Santiago.

Fernández, M. y J. Salinas (compil.). 2012. Defensa de los Derechos Territoriales en Latinoamérica. RIL, Santiago.

Folchi, M. 2003. La insustentabilidad del boom minero chileno: política y medio ambiente, 1983-2003. Ecología Política 26:23-49.

Gentes, I. 2004. Estudio de la Legislación Oficial Chilena y del Derecho Indígena a los Recursos Hídricos. WALIR/CEPAL, Santiago.

Griem, W. 2003. El Valle de Copiapó, Región de Atacama, Los Loros (10 julio 2014). http://www.geovirtual2.cl/MVpaisaje/ Los-Loros-Atacama-01.htm (3 junio 2015).

Guajardo, J. 2007. La Agenda Minera en Chile: Revisión y Perspectivas. CEPAL, Santiago.

Gundermann, H. 2013. Los atacameños y sus relaciones interétnicas. En Pueblos Originarios y Sociedad Nacional en Chile. La Interculturalidad en las Prácticas Sociales, coordinado por J. Durston, pp. 81-97. PNUD, Santiago.

Gundermann, H., A. Ancapi y L. Barrios 2013. Aymara: las relaciones interétnicas. En Pueblos Originarios y Sociedad Nacional en Chile. La Interculturalidad en las Prácticas Sociales, coordinado por J. Durston, pp. 51-71. PNUD, Santiago.

Gundermann, H. y J. Vergara 2009. Comunidad, organización y complejidad social andinas en el norte de Chile. Estudios Atacameños 38:107-126.

Instituto Nacional de Derechos Humanos (INDH) 2012. Mapa de Conflictos Socioambientales en Chile. INDH. http://www.indh.cl/ mapa-de-conflictos-socioambientales-en-chile (8 agosto 2014).
Larraín, S. y P. Poo (eds.) 2010. Conflictos por el Agua en Chile. Entre los Derechos Humanos y las Reglas del Mercado. Chile Sustentable, Santiago.

Machado, H. 2010. Territorio, colonialismo y minería transnacional. Una hermenéutica crítica de las nuevas cartografías del imperio. Ponencia presentada en III Jornadas del Doctorado en Geografía. Desafíos Teóricos y Compromiso Social en la Argentina de Hoy, La Plata.

Malebrán, N. y M. Rodríguez 2014. Transformaciones en el Valle de Copiapó. Percepciones sobre el impacto de la agroindustria y la minería sobre el recurso hídrico en Los Loros. Revista Rufián 19:49-53.

McPhee, B. 2010. Conflictos ambientales y respuestas sociales: el caso de reetnificación de la comunidad de Quillagua. Revista Mad. Revista del Magíster en Análisis Sistémico Aplicado a la Sociedad 22:42-55.

Ministerio de Obras Públicas (MOP) 2013. Estrategia Nacional de Recursos Hídricos 2012-2025. MOP, Edición Digital. http:// www.mop.cl/Documents/ENRH_2013_OK.pdf, (8 agosto 2014).

Molina, R. 2012. Guía de Antecedentes Territoriales y Culturales de los Pueblos Indígenas de Chile. Dirección General de Obras Públicas, Santiago.

Molina, R. 2013. Los collas: identidad y relaciones interculturales en Atacama. En Pueblos Originarios y Sociedad Nacional en Chile. La Interculturalidad en las Prácticas Sociales, coordinado por J. Durston, pp. 99-113. PNUD, Santiago.

Núñez, M. 2000. Movimientos y Voces en Peine. Tesis para optar al grado de licenciada en Antropología y Título de Antropóloga. Escuela de Antropología, Universidad Academia de Humanismo Cristiano, Santiago.

Odone, M. 1995. Quillagua: La descripción de un espacio desde la historia. Actas II Congreso Chileno de Antropología Vol. 2, pp. 598-605. Universidad Austral de Chile, Valdivia.

Quiroz, D. y Y. Jeria 2010. Etnogénesis e identidad cultural entre los grupos colla de la Cordillera de Atacama. Boletín del Museo Regional de Atacama 1:25-42.

Sandoval, J. 2003. El Riego en Chile. Ministerio de Obras Públicas-Dirección de Obras Hidráulicas, Santiago.

Trinchero, H., A. Balazote y S. Valverde 2007. Antropología económica y ecológica: recorridos y desafíos disciplinares. Cuadernos de Antropología Social 26:7-19.

Valdés, X. 2012. Desincronización temporal y espacial entre trabajo y familia: Hacerse del salario en las migraciones estacionales de los/as temporeros/as de la uva. Polis 31 (24 julio 2012). http:// polis.revues.org/4230 (17 junio 2014).

Van Kessel, J. y H. Larraín 1997. Manos Sabias Para Criar la Vida. Tecnología Andina. Hombre y Ambiente, Quito.

Vargas, R. 2006. La Cultura del Agua. Lecciones de la América Indígena. UNESCO, Montevideo.

Wallerstein, I. 2003 [1983]. El Capitalismo Histórico. Quinta edición traducido por P. López. Siglo XXI, México D.F.

Wolf, E. 2000 [1982]. Europa y la Gente sin Historia. Segunda edición traducido por A. Bárcenas. FCE, Buenos Aires. 
Yáñez, N. y R. Molina 2008. La Gran Minería y los Derechos Indígenas en el Norte de Chile. LOM, Santiago.
Yáñez, N. y R. Molina 2011. Las Aguas Indígenas en Chile. LOM, Santiago.

\section{Notas}

1 Proyecto "Minería, agricultura y la dimensión cultural de los conflictos territoriales por las aguas" (responsable Miguel Bahamondes), Concurso de Núcleos Temáticos de Investigación, Universidad Academia de Humanismo Cristiano.

2 Siguiendo conceptualizaciones previas (Calderón et al. 2013), entendemos el neoliberalismo como una fase del desenvolvimiento capitalista sobre la base de ciclos de expansión y crisis dentro de un esquema global centroperiferia. Frente a la crisis que comienza entre 1967/1973, el neoliberalismo es la reacción del gran capital para posicionarse ventajosamente. Como modelo económicopolítico implica una reducción del Estado de la vida económica mediante privatizaciones y flexibilización de mercados.

3 Debe distinguirse entre la "comunidad jurídica" -figura de comunidad indígena impuesta por el Estado chileno mediante la Ley 19.253- y la "comunidad sociológica", forma histórica de organización colectiva andina, institución social, económica y política que articula las relaciones al interior de los poblados y el acceso a los recursos por medio de unidades familiares emparentadas entre sí (Gundermann y Vergara 2009).
4 El año de constitución legal de esta comunidad no ha sido identificado. Analizando bibliografía actualizada su conformación debería ser posterior al 2011 (Molina 2012; Quiroz y Jeria 2010).

5 En el CA de 1981 las aguas son bienes públicos, empero se crean a favor de los privados los derechos de aprovechamiento, los cuales son entregados gratuitamente por el Estado, permitiendo su uso y comercialización con plena libertad, homologándolos al derecho de propiedad (Gentes 2004).

6 Acerca de la problemática en Quillagua ver Carmona (2013, 2014).

7 Para este amplísimo tema en Chile y el mundo andino ver Castro et al. (1992), Castro y Martínez (1996), van Kessel y Larraín (1997) y Yáñez y Molina (2011).

8 Respecto de la problemática en Peine ver Benavides y Sinclair (2014a, 2014b).

9 Concerniente a la problemática en Los Loros ver Malebrán y Rodríguez (2014).

10 Actualmente la de mayor producción en el país superando a la estatal Chuquicamata. El 2012 produjo 1.075 .825 toneladas mientras Chuquicamata alcanzó 355.000. El total de las ocho operaciones de CODELCO fue de 1.646.000 toneladas (COCHILCO 2012 en Benavides y Sinclaire 2014a). 
